\title{
Comparison of Tadalafil and Sildenafil in Controlling Neonatal Persistent Pulmonary Hypertension
}

\author{
Mohammad Reza Alipour, ${ }^{1}$ Mohammad Hossein Lookzadeh, ${ }^{1}$ Seyedeh Mahdieh Namayandeh, ${ }^{1}$ \\ Zohreh Pezeshkpour,,* and Mohammadtaghi Sarebanhassanabadi ${ }^{1}$ \\ ${ }^{1}$ Yazd Cardiovascular Research Center, Shahid Sadoughi University of Medical Sciences, Yazd, IR Iran \\ "Corresponding author: Zohreh Pezeshkpour, Afshar Hospital, Jomhouri Blvd., Yazd, IR Iran. Tel: +98-3535231421, Fax: +98-3535253335, E-mail: z.pezeshkpour@yahoo.com
}

Received 2016 April 14; Revised 2016 May 25; Accepted 2016 August 12.

\begin{abstract}
Background: Persistent pulmonary hypertension of the newborn (PPHN) occurs in post-term neonates with an incidence of 1 in 500 - 1,500 live births. The survival rate is approximately $69 \%$ after conventional management of infants suffering from PPHN. Extracorporeal membrane oxygenation (ECMO) therapy improves survival up to $86 \%$.

Methods: A total of 32 neonates with PPHN participated in this study. These neonates were randomly assigned into two 16-case groups: group A received tadalafil while group B received sildenafil. A random simple sampling method was used for the selection of subjects. The severity of tricuspid regurgitation (TR), main pulmonary artery (MPA) diameter, mean pulmonary artery pressure (MPAP), and right ventricular end-diastolic diameter (RVEDD) were assessed by echocardiography before and 6 months after treatment.

Results: MPAP decreased after treatment in both groups, but the mean of changes in PAP in the two groups was not significantly different $(P=0.48)$. Both tadalafil and sildenafil significantly reduced the TR severity, RVEDD, and MPA diameter $(P<0.05)$, but the mean of the changes in TR, RVEDD, and MPA in both groups was similar $(\mathrm{P}=0.05)$.

Conclusions: Tadalafil and sildenafil can similarly reduce MPAP, TR severity, RVEDD, and MPA diameter.
\end{abstract}

Keywords: Persistent Pulmonary Hypertension, Tadalafil, Sildenafil

\section{Background}

Postnatal pulmonary hypertension is a rare sporadic disease in neonates and infants, and is associated with high morbidity and mortality. Few studies have focused on this population (1). PPHN is defined as postnatal failure in the normal cardiopulmonary blood circulation(2) leading to hypoxia secondary to right-to-left shunt accompanied with prenatal distress. These signs and symptoms include asphyxia, tachypnea, respiratory distress, long $\mathrm{S}_{2}$, low Apgar score, meconium acetin, cyanosis, weak cardiac function, systemic hypotension, and shock $(3,4)$. Persistent pulmonary hypertension of the newborn (PPHN) occurs in post-term neonates (5), with an incidence of 1 in 500 1,500 live births (6). In advanced pulmonary hypertension, structural and functional changes in the pulmonary vessels result in increased pulmonary vessel resistance, right ventricular failure, and death (1). The goal of medical treatment is to dilate and reverse the abnormal remodeling of the vascular floor of the lungs and to maintain endothelial function by the action of prostacyclin, endothelin, and the nitric oxide (NO) pathway. The therapeutic algorithm and pulmonary artery hypertension (PAH) in children are virtually similar to those in adults (7-9).
Medical management includes preventing or treating the active pulmonary vasoconstriction, supporting right ventricular function, and preventing structural changes in the pulmonary vessels (1). The treatments currently used include prostacyclin $(10,11)$, milierinon $(12,13)$, NO $(14,15)$, and bosentan (16). Since the neurohormonal activity of the sympathetic system has been implicated in pulmonary hypertension, digoxin may also be valuable in this regard due to its sympathetolytic effects $(17,18)$. The 5phosphodiesterase (5-PDE) inhibitors have been also used for this purpose (19). These medicines exert some beneficial effects on the vascular system, including vasodilation, inhibition of smooth muscle proliferation, and prevention of platelet accumulation (20). The inhibition of 5PDE, which metabolizes cyclic guanosine monophosphate (cGMP), reduces the pulmonary and systemic pressures under physiologic conditions $(21,22)$. Additionally, in animal and human models of pulmonary hypertension, these drugs decrease pulmonary hypertension to a greater degree through the relatively selective inhibition of the pulmonary vascular system compared to systemic vascular resistance $(23,24)$. It was because of these beneficial effects that sildenafil was used as the first 5-PDE inhibitor (5-PDEI) 
drug for treating pulmonary hypertension that was capable of improving the cardiac index and exercise capacity (25). Tadalafil is a 5-PDEI analog with a longer half-life, of approximately 17.5 hours. It was approved for use in treating pulmonary hypertension in adults in 2009 (26). Tadalafil can be used as a safe medicine for improving functional capacity and providing better oxygenation saturation in infants and adults, without significant complications and with fewer daily doses compared to sildenafil (27). It has been proposed that tadalafil has benefits similar to those of sildenafil, with fewer complications in PPHN patients (28). These findings led us to investigate the effects of tadalafil in reducing TR severity, mean pulmonary artery pressure (MPAP), right ventricular end-diastolic diameter (RVEDD), and main pulmonary artery (MPA) diameter in neonates with PPHN, and to compare this drug to sildenafil.

\section{Methods}

A total of 32 neonates with PPHN participated in this study. PPHN was defined as cyanosis in neonates admitted to the NICU, which continued after 30 minutes of ventilation with $100 \% \mathrm{O}_{2}$ via hood. If the $\mathrm{PaO}_{2}$ level was $20 \mathrm{mmHg}$ in the radial artery and greater than in the umbilical or femoral arteries, the patient was referred to echocardiography for confirmation of a right-to-left or two-sided shunt. Pulse oximetry of the right hand and foot was performed if an arterial line was not accessible. If pulse oximetry of the hand was $5 \%$ more than that of the foot, the patient was referred to echocardiography.

These neonates were randomly assigned into two 16case groups: group A received tadalafil and group B received sildenafil. A random simple sampling method was used for subject selection. Sildenafil was administered orally, $1 \mathrm{mg} / \mathrm{kg}$ three times/day. Tadalafil was also administered orally, $1 \mathrm{mg} / \mathrm{kg}$ as a single dose (29).

PAP was measured via echocardiography based on gradient of pulmonary insufficiency (PI) or gradient of TR (tricuspid regurgitation) on Doppler echocardiography. The severity of TR, MPA diameter, and RVEDD were assessed by echocardiography before and 6 months after treatment. TR severity is the volume of blood regurgitated via the tricuspid valve in systole, and is measured by the amount of color jet seen during color echocardiography. In other words, mild TR means that the amount of color jet covers one third of the surface of the right atrium (RA), moderate TR means that the amount of color jet covers two-thirds of the RA surface, and severe TR depicts the amount of color jet when it covers more than two thirds of the RA surface. MPA diameter and RVEDD were measured on 2D echocardiography.
This procedure was performed by one cardiologist, who was blind to the study. The triple-blind design was carried out via blinding of the participants, the cardiologist who performed the echocardiography, and the statistician who analyzed the data. Concealment of treatment allocation was done before drug administration. No conflicts of interest of the authors existed. According to research ethics, this study was approved by the local ethics committee of Yazd Shahid Sadoughi University of Medical Sciences.

\section{Results}

Thirty-two neonates were enrolled in this study based on the inclusion criteria. The etiology of PPHN was meconium aspiration in 19 (59.3\%) neonates, diaphragmatic herniation in three (9.3\%) neonates, and asphyxia in 10 (31.2\%) neonates. In group A, the mean of changes in MPAP before and after treatment was $14.56 \pm 8.6 \mathrm{mmHg}(\mathrm{P}<0.0001)$. In group $\mathrm{B}$, the mean of changes in PAP was $12.75 \pm 5.5 \mathrm{mmHg}$ $(\mathrm{P}<0.0001)$. Moreover, the mean of changes in MPAP in the two groups was similar $(\mathrm{P}=0.48)$. Tadalafil significantly reduced TR severity $(\mathrm{P}<0.0001)$. Sildenafil also significantly reduced TR severity $(\mathrm{P}<0.0001)$. The effects of tadalafil and sildenafil on TR were similar $(\mathrm{P}=0.38)$. Tadalafil decreased the mean RVEDD by $6.87 \pm 3.1 \mathrm{~mm}(\mathrm{P}<0.0001)$; however, the mean RVEDD decreased by $6.25 \pm 3.2 \mathrm{~mm}(\mathrm{P}<0.0001)$. This difference was similar in both groups $(\mathrm{P}=0.58)$. Regarding MPA diameter, tadalafil reduced it by $4 \pm 1.6 \mathrm{~mm}$ $(\mathrm{P}<0.0001)$, while sildenafil reduced it by $3 \pm 1.3 \mathrm{~mm}(\mathrm{P}<$ 0.0001). Therefore, the effects of tadalafil and sildenafil on decrements of MPA diameter were similar $(\mathrm{P}=0.07)$.

Table 1 shows the similarity of the effects of tadalafil and sildenafil on MPAP, TR severity, RVEDD, and MPA diameter in neonates with PPHN. No side effects were seen in any group.

Table 1. Comparison of the Effects of Tadalafil and Sildenafil on MPAP, TR Severity, RVEDD, and MPA Diameter in Neonates with PPHN

\begin{tabular}{lccc}
\hline \multirow{2}{*}{ Mean changes } & \multicolumn{2}{c}{ Treatment } & \multirow{2}{*}{ P Value } \\
\cline { 2 - 3 } & Group A & Group B & \\
\hline MPAP & Tadalafil Mean (SD) & Sildenafil Mean (SD) \\
\hline TR severity & $-14.56(8.6)$ & $-12.75(5.5)$ & 0.48 \\
\hline RVEDD & $-0.87(0.5)$ & $-1.06(0.68)$ & 0.38 \\
MPA diameter & $-6.8(3.13)$ & $-6.25(3.23)$ & 0.58 \\
\hline
\end{tabular}




\section{Discussion}

The effects of tadalafil and sildenafil on MPAP, TR severity, RVEDD, and MPA diameter in neonates with PPHN were similar. Tadalafil has recently been used for treatment of PAH in humans (19) and can be safely used in children (30). Tadalafil has been used in adults with similar efficacy, but its use is not common in children (27). In the present study, no side effects were seen in any group. Sabri et al. showed that tadalafil may be a safe drug for children and young adults with PAH, and did not observe any significant side effects. Tadalafil also requires fewer daily doses than sildenafil (27). Tadalafil and sildenafil showed similar effects on MPAP, TR severity, RVEDD, and MPA diameter in neonates. Tadalafil was recently used for treatment of PAH in humans, including children. In 2009, tadalafil was approved for PAH treatment (31).

A previous study suggested that the relationship between the NO pathway and pulmonary circulation was greater than the effect of NO on the endothelium. This, along with the mechanism of action of drugs, can justify these findings (27). In a study by Takatsuki et al., only two patients stopped taking tadalafil due to side effects, which included migraines and allergic reactions. Thus, the discontinuation rate for tadalafil therapy in children was $6 \%$ (30). In a study by Shiva et al. conducted on 25 patients aged two months to five years, a significant improvement was seen in MPAP $(\mathrm{P}<0.01)(29)$. They used tadalafil $1 \mathrm{mg} / \mathrm{kg}$ daily. After changing from sildenafil to tadalafil, a significant clinical improvement was seen $(\mathrm{P}<0.05)$. It was also obvious that the use of an oral tadalafil suspension was safe and well-tolerated (29). Unlike sildenafil, the longer halflife of tadalafil makes serum levels more consistent, which may have an advantage with regard to hemodynamics in patients with PAH (30). Tessler et al. showed that PAP decreased on average by $54 \%$ in experimental animals after administration of $1 \mathrm{mg} / \mathrm{kg}$ of oral tadalafil, and cardiac output increased by $88 \%$ following tadalafil administration in newborn piglets (31).

Moreover, Takatsuki et al. extrapolated the pediatric dose for this study from adult studies. They applied tadalafil $0.2 \mathrm{mg} / \mathrm{kg}$ daily according to estimations from the aforementioned study (30). In a newborn animal model of acute pulmonary hypertension, oral tadalafil administration reduced pulmonary vascular resistance and increased arterial oxygenation by increasing cardiac output and reducing the lung shunt fraction (31). Our study was the first to use tadalafil in human newborns, and more research is needed to explore this issue.

\section{Footnote}

Authors' Contribution: Analysis and interpretation of data, Mohammad Reza Alipour and Seyedeh Mahdieh Namayandeh; drafting of the manuscript, Mohammad Reza Alipour, and Mohammadtaghi Sarebanhassanabadi; critical revision of the manuscript for important intellectual content, Mohammad Reza Alipour, Mohammadtaghi Sarebanhassanabadi, and Zohreh Pezeshkpour; statistical analysis, Mohammad Reza Alipour and Seyedeh Mahdieh Namayandeh.

\section{References}

1. Oishi P, Datar SA, Fineman JR. Advances in the management of pediatric pulmonary hypertension. Respir Care. 2011;56(9):1314-39. doi: 10.4187/respcare.01297. [PubMed: 21944683].

2. Steinhorn RH. Neonatal pulmonary hypertension. Pediatr Crit Care Med. 2010;11(2 Suppl):S79-84. doi: 10.1097/PCC.0b013e3181c76cdc. [PubMed: 20216169].

3. Teixeira-Mendonca C, Henriques-Coelho T. Pathophysiology of pulmonary hypertension in newborns: therapeutic indications. Rev Port Cardiol. 2013;32(12):1005-12. doi: 10.1016/j.repc.2013.06.010. [PubMed: 24280076].

4. Morin FC, Stenmark KR. Persistent pulmonary hypertension of the newborn. Am J Respirat Crit Care Med. 1995;151(6):2010-32.

5. Derleth DP. Treatment of persistent pulmonary hypertension in the neonate. J pediatr. 1992;120(6):1004.

6. Delsing B, Lopriore E, Blom N, Te Pas AB, Vandenbussche FP, Walther FJ. Risk of persistent pulmonary hypertension of the neonate in twinto-twin transfusion syndrome. Neonatology. 2007;92(2):134-8. doi: 10.1159/000101433. [PubMed: 17396038].

7. Galie N, Hoeper MM, Humbert M, Torbicki A, Vachiery JL, Barbera JA, et al. Guidelines for the diagnosis and treatment of pulmonary hypertension: the Task Force for the Diagnosis and Treatment of Pulmonary Hypertension of the European Society of Cardiology (ESC) and the European Respiratory Society (ERS), endorsed by the International Society of Heart and Lung Transplantation (ISHLT). Eur Heart J. 2009;30(20):2493-537. doi: 10.1093/eurheartj/ehp297. [PubMed: 19713419].

8. Barst RJ, Gibbs JS, Ghofrani HA, Hoeper MM, McLaughlin VV, Rubin LJ, et al. Updated evidence-based treatment algorithm in pulmonary arterial hypertension. J Am Coll Cardiol. 2009;54(1 Suppl):S78-84. doi: 10.1016/j.jacc.2009.04.017. [PubMed: 19555861].

9. Ivy DD, Feinstein JA, Humpl T, Rosenzweig EB. Non-congenital heart disease associated pediatric pulmonary arterial hypertension. Prog Pediatr Cardiol. 2009;27(1-2):13-23. doi: 10.1016/j.ppedcard.2009.09.004. [PubMed: 21852894].

10. Kumar VH, Swartz DD, Rashid N, Lakshminrusimha S, Ma C, Ryan $\mathrm{RM}$, et al. Prostacyclin and milrinone by aerosolization improve pulmonary hemodynamics in newborn lambs with experimental pulmonary hypertension. J Appl Physiol (1985). 2010;109(3):677-84. doi: 10.1152/japplphysiol.01082.2009. [PubMed: 20616229].

11. Kelly LK, Porta NF, Goodman DM, Carroll CL, Steinhorn RH. Inhaled prostacyclin for term infants with persistent pulmonary hypertension refractory to inhaled nitric oxide. J Pediatr. 2002;141(6):830-2. doi: 10.1067/mpd.2002.129849. [PubMed: 12461501].

12. Lakshminrusimha S, Porta NF, Farrow KN, Chen B, Gugino SF, Kumar $\mathrm{VH}$, et al. Milrinone enhances relaxation to prostacyclin and iloprost in pulmonary arteries isolated from lambs with persistent pulmonary hypertension of the newborn. Pediatr Crit Care Med. 2009;10(1):106-12. doi: 10.1097/PCC.ob013e3181936aee. [PubMed: 19057444]. 
13. McNamara PJ, Shivananda SP, Sahni M, Freeman D, Taddio A. Pharmacology of milrinone in neonates with persistent pulmonary hypertension of the newborn and suboptimal response to inhaled nitric oxide. Pediatr Crit Care Med. 2013;14(1):74-84. doi: 10.1097/PCC.0b013e31824ea2cd. [PubMed: 23132395].

14. Steinhorn RH. Nitric oxide and beyond: new insights and therapies for pulmonary hypertension. J Perinatol. 2008;28 Suppl 3:S67-71. doi: 10.1038/jp.2008.158. [PubMed: 19057613].

15. Steinhorn RH. Therapeutic approaches using nitric oxide in infants and children. Free Radic Biol Med. 2011;51(5):1027-34. doi: 10.1016/j.freeradbiomed.2011.01.006. [PubMed: 21237265].

16. Latus H, Delhaas T, Schranz D, Apitz C. Treatment of pulmonary arterial hypertension in children. Nat Rev Cardiol. 2015;12(4):244-54. doi: 10.1038/nrcardio.2015.6. [PubMed: 25645500].

17. Pan D, Rubin GM. Kuzbanian controls proteolytic processing of Notch and mediates lateral inhibition during Drosophila and vertebrate neurogenesis. Cell. 1997;90(2):271-80. [PubMed: 9244301]

18. Rich S, Seidlitz M, Dodin E, Osimani D, Judd D, Genthner D, et al. The short-term effects of digoxin in patients with right ventricular dysfunction from pulmonary hypertension. Chest. 1998;114(3):787-92. [PubMed: 9743167].

19. Hori Y, Kondo C, Matsui M, Yamagishi M, Okano S, Chikazawa S, et al. Effect of the phosphodiesterase type 5 inhibitor tadalafil on pulmonary hemodynamics in a canine model of pulmonary hypertension. Vet J. 2014;202(2):334-9. doi:10.1016/j.tvjl.2014.08.009. [PubMed: 25178687].

20. Bender AT, Beavo JA. Cyclic nucleotide phosphodiesterases: molecular regulation to clinical use. Pharmacol Rev. 2006;58(3):488-520. doi: 10.1124/pr.58.3.5. [PubMed: 16968949].

21. Jackson G, Benjamin N, Jackson N, Allen MJ. Effects of sildenafil citrate on human hemodynamics. Am J Cardiol. 1999;83(5A):13C-20C. [PubMed: 10078538].

22. Madhani M, Okorie M, Hobbs AJ, MacAllister RJ. Reciprocal regulation of human soluble and particulate guanylate cyclases in vivo. Br J Pharmacol. 2006;149(6):797-801. doi: 10.1038/sj.bjp.0706920. [PubMed: 17016498].

23. Klinger JR, Thaker S, Houtchens J, Preston IR, Hill NS, Farber HW. Pul- monary hemodynamic responses to brain natriuretic peptide and sildenafil in patients with pulmonary arterial hypertension. Chest. 2006;129(2):417-25. doi:10.1378/chest.129.2.417. [PubMed: 16478861].

24. Baliga RS, Zhao L, Madhani M, Lopez-Torondel B, Visintin C, Selwood D, et al. Synergy between natriuretic peptides and phosphodiesterase 5 inhibitors ameliorates pulmonary arterial hypertension. Am J Respir Crit Care Med. 2008;178(8):861-9. doi: 10.1164/rccm.2008011210C. [PubMed: 18689467].

25. Galie N, Ghofrani HA, Torbicki A, Barst RJ, Rubin LJ, Badesch D, et al Sildenafil citrate therapy for pulmonary arterial hypertension. NEngl J Med. 2005;353(20):2148-57. doi: 10.1056/NEJMoa050010. [PubMed: 16291984].

26. Galie N, Brundage BH, Ghofrani HA, Oudiz RJ, Simonneau G, Safdar Z, et al. Tadalafil therapy for pulmonary arterial hypertension. Circulation. 2009;119(22):2894-903. doi: 10.1161/CIRCULATIONAHA.108.839274. [PubMed: 19470885].

27. Sabri MR, Beheshtian E. Comparison of the therapeutic and side effects of tadalafil and sildenafil in children and adolescents with pulmonary arterial hypertension. Pediatr Cardiol. 2014;35(4):699-704. doi: 10.1007/s00246-013-0840-z. [PubMed: 24253611].

28. Lichtblau M, Harzheim D, Ehlken N, Marra A, Pinado FP, Grunig E, et al. Safety and long-term efficacy of transition from sildenafil to tadalafil due to side effects in patients with pulmonary arterial hypertension. Lung. 2015;193(1):105-12. doi: 10.1007/s00408-014-9657-7. [PubMed: 25318865].

29. Shiva A, Shiran M, Rafati M, Zamani H, Babazadeh K, Saeedi M, et al. Oral Tadalafil in Children with Pulmonary Arterial Hypertension. Drug Res (Stuttg). 2016;66(1):7-10. doi: 10.1055/s-0034-1395510. [PubMed: 25611962].

30. Takatsuki S, Calderbank M, Ivy DD. Initial experience with tadalafil in pediatric pulmonary arterial hypertension. Pediatr Cardiol. 2012;33(5):683-8. doi: 10.1007/s00246-012-0180-4. [PubMed: 22402804]

31. Tessler RB, Zadinello M, Fiori H, Colvero M, Belik J, Fiori RM Tadalafil improves oxygenation in a model of newborn pulmonary hypertension. Pediatr Crit Care Med. 2008;9(3):330-2. doi: 10.1097/PCC.0b013e31816c7035. [PubMed: 18446109]. 